http://jmscr.igmpublication.org/home/ ISSN (e)-2347-176x ISSN (p) 2455-0450

crossref DOI: https://dx.doi.org/10.18535/jmscr/v8i11.06

Journal Of Medical Science And Clinical Research

\title{
Clinicopathological Features and Outcome of Varicose Veins - A Prospective Study
}

\author{
Authors
Dr Aravindhan.M ${ }^{1 *}$, Dr Kabalimurthy.J ${ }^{2}$, Dr Sundar Prakash.S ${ }^{3}$, Dr Jospin Amala $\mathbf{A}^{1}$, Dr Kamal Kumar ${ }^{1}$, Dr Mary Prescilla ${ }^{1}$ \\ ${ }^{1}$ Junior Resident, ${ }^{2}$ Professor and Chief, ${ }^{3}$ Associate Professor \\ Department of General Surgery, Rajah Muthiah Medical college and Hospital, Annamalai University, \\ Tamil Nadu, India \\ *Corresponding Author
}

Dr Aravindhan.M

\begin{abstract}
Background: The study was conducted to study the various etiological, anatomical and pathological factors for varicose veins. To study the clinical patterns of varicose veins and comparing their occurrence with etiological factors and to study the relevance of various investigative modalities for varicose veins.

Materials and Methods: This study was conducted in 52 patients diagnosed with varicose veins who were admitted in the department of General Surgery, Rajah Muthiah Medical College from October 2018 to September 2020.

Results: Out of 52 patients, those who presented with C4 classification are highest. Primary etiology was much common than secondary. Pathologically, reflux type was common then obstructive type. Anatomically GSV and perforator combination was more common.

Conclusion: In this study, Clinical presentations in varicose veins ranged from mild to severe varicosities, with ulcer and lipodermatosclerosis being the most severe forms. At present, Duplex ultrasound scanning is the most reliable investigative tool in making diagnosis of varicose veins. Treatment includes conservative management, sclerotherapy and surgery. Surgical intervention has been revolutionized by the development of endovenous techniques like radiofrequency abalation, laserabalation, foamsclerotherapy and subfacial endoscopic perforator surgery.
\end{abstract}

Keywords: Varicose veins, GSV, perforator, Doppler, trendelenberg.

\section{Introduction}

Varicose veins refers to any dilated, tortuous, elongated vein of any caliber of the limb. The term varicose veins, in the common prevalence, is a term that encompasses a spectrum of venous dilation that ranges from minor telangiectasia to severe dilated veins. Telangiectasias are intra dermal varicosities that are small of about less than $1 \mathrm{~mm}$ in size and tend to be cosmetically unappealing but not symptomatic. Reticular veins are subcutaneous dilated veins with size of about 1to $3 \mathrm{~mm}$ that enter the tributaries of the main axial or trunk veins. Varicose veins of lower limbs are the penalty, man has to pay for his upright posture. These conditions are associated with high morbidity even though mortality may not be significant. Twenty percent of the Indian population suffers from varicose veins. High rate 
of recurrence of varicose veins after surgery, difficulty in surgery warranty thorough clinical examination, complete investigation to rule out any underlying cause and optimal treatment.

\section{Materials and Methods}

The study was conducted in the Department of General Surgery, Rajah Muthiah Medical College and Hospital diagnosed with varicose veins. The period of study is from October 2018 to September 2020 (2 years). The sample size is 52 . In this study, patients admitted with diagnosis of secondary varicose vein other than deep vein thrombosis and patients with recurrent varicose veins have been excluded.

\section{Statistical Method}

The demographic data collected and analysed. The percentage pattern calculated for profile of "Clinicopathological Features and Outcome of Varicose Veins". The data obtained by the various parameters are statistically calculated by using SPSS 20 version software and the $\mathrm{p}$ value calculated is less than 0.05 is considered significant. Wherever necessary, the data will be depicted using tables and figures

\section{Results}

Table 1: Symptoms

\begin{tabular}{|l|c|c|}
\hline \multicolumn{1}{|c|}{ Symptoms } & Frequency & Percent \\
\hline Pain, prominent vein & 10 & 19.2 \\
\hline Pain, prominent vein, Pigmentation & 2 & 3.8 \\
\hline Prominent vein & 10 & 19.2 \\
\hline Prominent vein, Pigmentation & 14 & 26.9 \\
\hline Ulcer, pigmentation & 6 & 11.5 \\
\hline Ulcer, prominent vein, Pigmentation & 10 & 19.2 \\
\hline
\end{tabular}

Graph 1: Symptoms

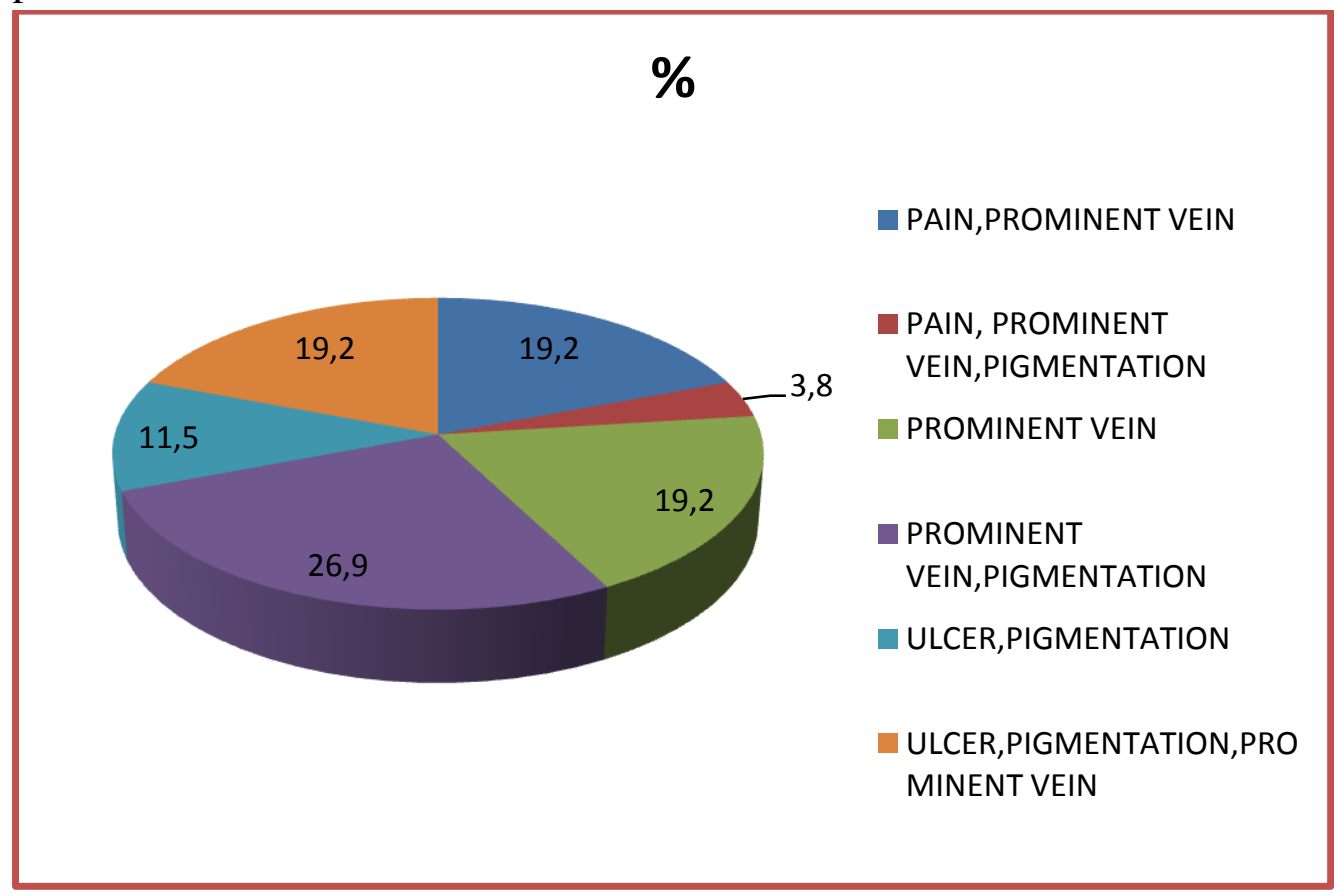

Table 2: Affected Limbs

\begin{tabular}{|l|c|c|}
\hline Affected limb & Frequency & Percent \\
\hline Bilateral & 6 & 11.5 \\
\hline Unilateral & 46 & 88.5 \\
\hline
\end{tabular}


Graph 2: Affected Limbs

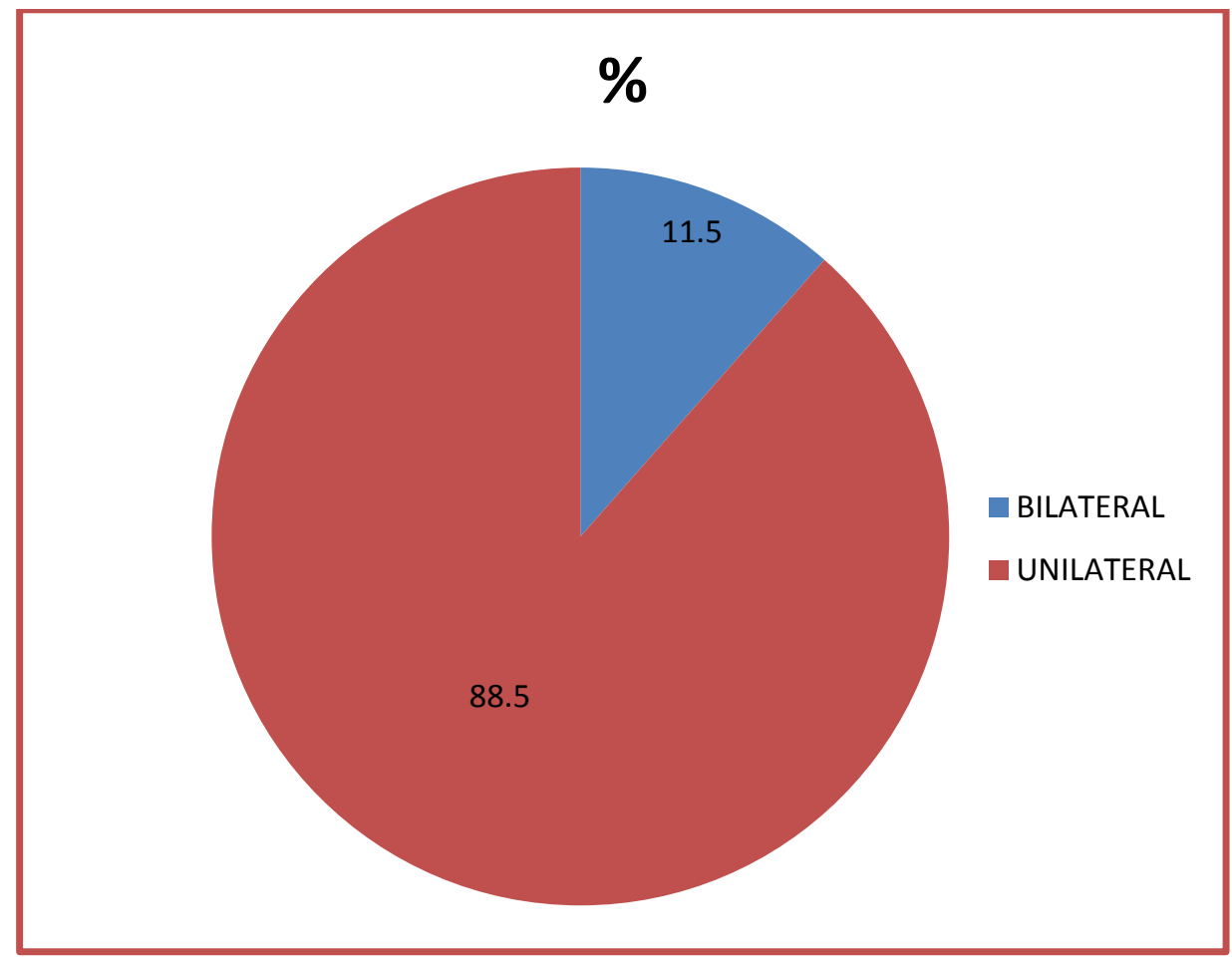

Table 3: Clinical Classification

\begin{tabular}{|c|c|c|}
\hline Clinical & Frequency & Percent \\
\hline $\mathrm{C} 2$ & 10 & 19.2 \\
\hline $\mathrm{C} 3$ & 10 & 19.2 \\
\hline $\mathrm{C} 4$ & 16 & 30.8 \\
\hline C5 & 8 & 15.4 \\
\hline C6 & 8 & 15.4 \\
\hline
\end{tabular}

Graph 3: Clinical Classification

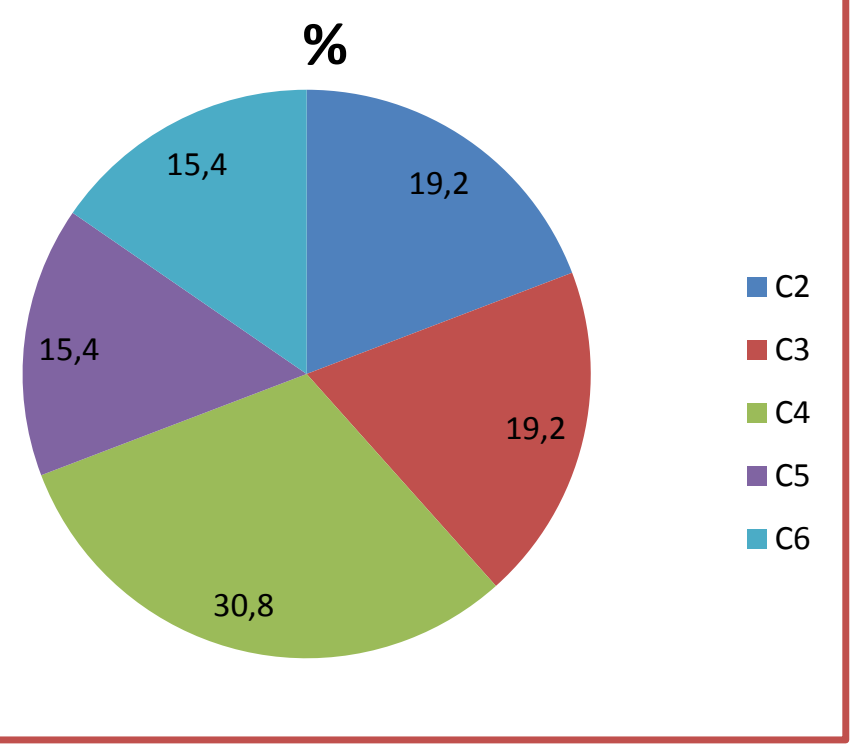

Table 4: Etiological Classification

\begin{tabular}{|l|l|l|}
\hline Etiological & Frequency & Percent \\
\hline Primary & 49 & 94.2 \\
\hline Secondary & 3 & 5.8 \\
\hline
\end{tabular}


Graph 4: Etiological Classification

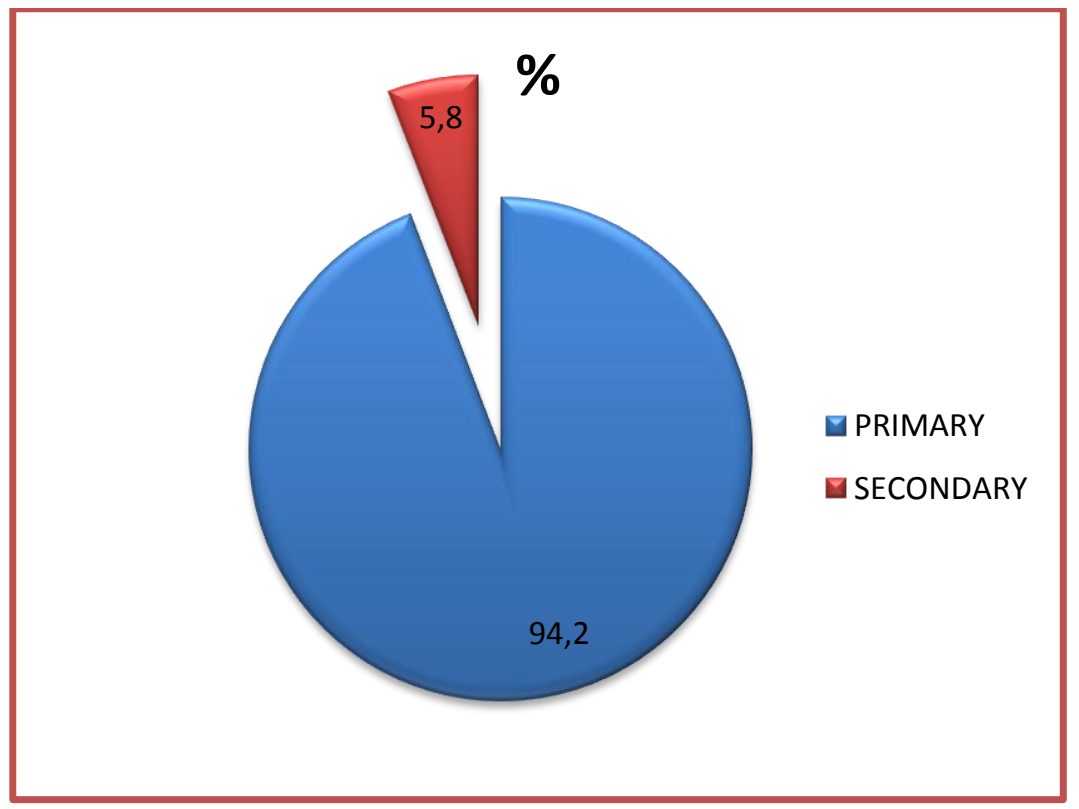

Table 5: Anatomical Classification

\begin{tabular}{|l|c|c|}
\hline Anatomical & Frequency & Percent \\
\hline GSV & 14 & 26.9 \\
\hline GSV, Perforator & 29 & 55.8 \\
\hline GSV, Perforator, Deep Vein & 3 & 5.8 \\
\hline SSV,GSV, Perforator & 6 & 11.5 \\
\hline
\end{tabular}

Graph 5: Anatomical Classification

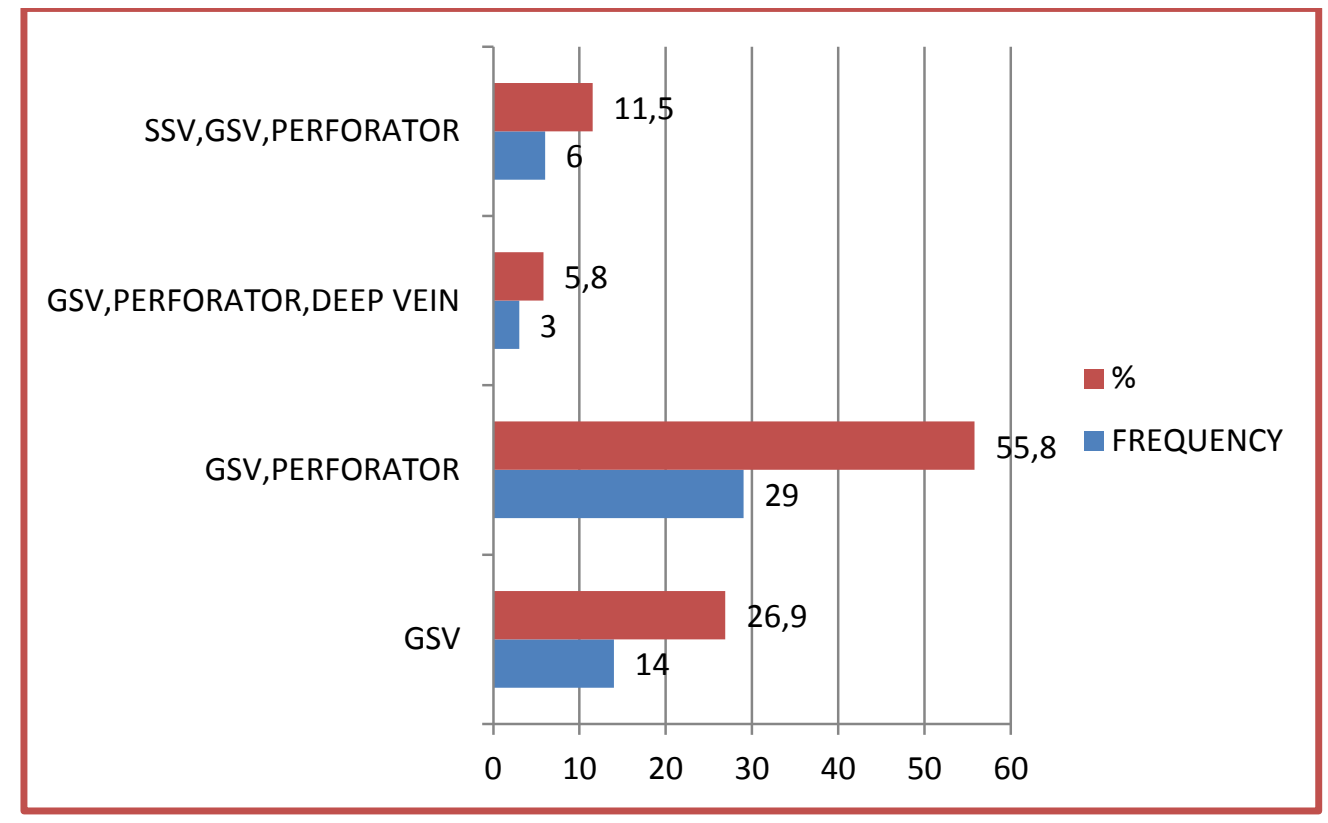

Table 6: Pathological Classification

\begin{tabular}{|c|c|c|}
\hline Pathological & Frequency & Percent \\
\hline Obstruction & 3 & 5.8 \\
\hline Reflux & 49 & 94.2 \\
\hline
\end{tabular}


Graph 6: Pathological Classification

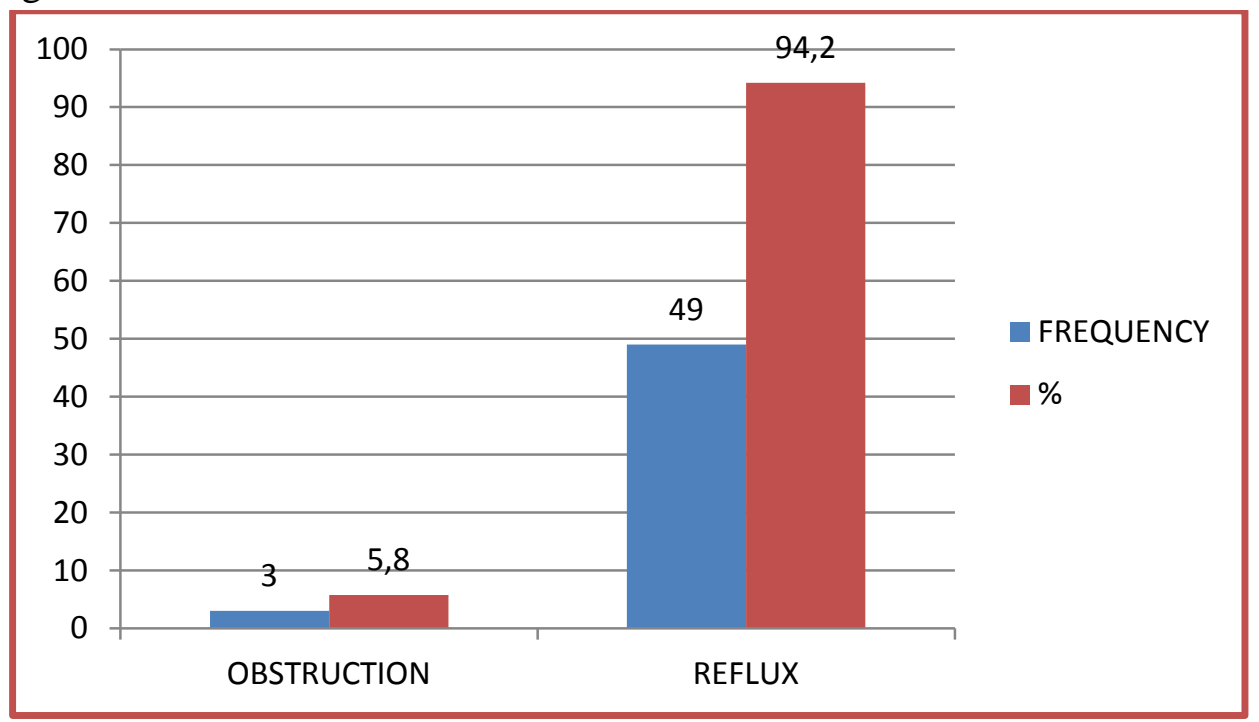

Table 7: Doppler Findings

\begin{tabular}{|l|c|c|}
\hline Doppler finding & Frequency & Percent \\
\hline $\begin{array}{l}\text { SFJ and perforator } \\
\text { Incompetence }\end{array}$ & 29 & 55.8 \\
\hline $\begin{array}{l}\text { SFJ and perforator } \\
\text { Incompetence, DVT present }\end{array}$ & 3 & 5.7 \\
\hline SFJ incompetence & 14 & 26.9 \\
\hline $\begin{array}{l}\text { SPJ , SFJ and perforator } \\
\text { Incompetence }\end{array}$ & 6 & 11.5 \\
\hline
\end{tabular}

Graph 7: Doppler Findings



Table 8: Surgery

\begin{tabular}{|c|c|c|}
\hline Surgery & Frequency & Percent \\
\hline Conservative management & 3 & 5.7 \\
\hline Trendelenberg procedure & 14 & 26.9 \\
\hline $\begin{array}{c}\text { Trendelenberg procedure and } \\
\text { Stab avulsion }\end{array}$ & 35 & 67.3 \\
\hline
\end{tabular}


Graph 8: Surgery

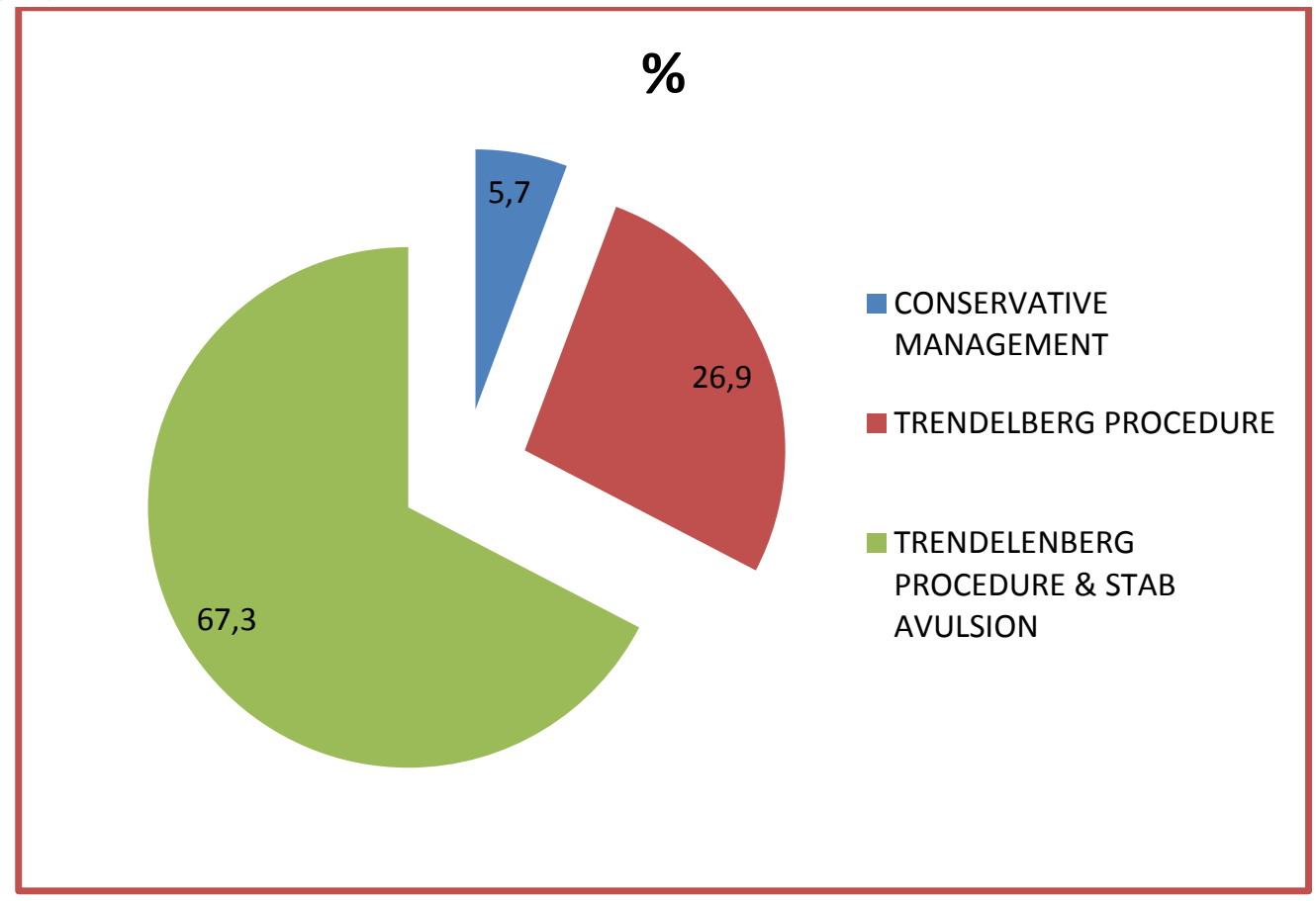

\section{Discussion}

Analysis of Symptoms and Affected Limbs: Prominent vein and pigmentation combined accounts for about $26.9 \%$.Prominent vein alone/ pain and prominent vein/ prominent vein, pigmentation and ulcer/ these combination of symptoms account for about $19.2 \%$. Even though symptoms occur in many combinations patients mainly comes with the complain of Prominent vein and pigmentation. Unilateral varicose vein $88.5 \%$ and bilateral disease is $11.5 \%$. Majority of cases included in study are primary varicose vein indicating that unilateral involvement is common in primary varicose veins.

Analysis of Clinical Classification: Analysis of this classification reveal that patients presents with $\mathrm{C} 4$ classification with a percentage of about $30.8 \%$ and next comes $\mathrm{C} 3$ and $\mathrm{C} 2$ classification which comes about $19.2 \%$. But the problem is that even though $\mathrm{C} 4$ appears maximum patient with C4 may even have lower grading C2 and C3 associated with it. This can be overcome by using advanced CEAP classification in which if the patient has dilated veins, edema and pigmentation the clinical classification comes as $\mathrm{C} 2 \mathrm{C} 3 \mathrm{C} 4$ instead $\mathrm{C} 4$ alone. Hence correct clinical picture of patients can be made out.

Analysis of Etiological Classification: In the etiological classification majority of the patients come under primary varicose veins accounting for 49 patients that is $94.2 \%$. Since in our study we excluded secondary varicose veins except which occurring secondary to DVT primary varicose vein mounts to such high percentage. The remaining cause being 5.8\% secondary to DVT.

Analysis of Anatomical Classification: In this study analysis of anatomical classification suggest most common veins involved are GSV and Perforator combination accounting for about 29 patients that is $55.8 \%$. Next comes involvement of GSV alone accounts for 14 patients that is $26.9 \%$. SSV and deep vein is also involved in some cases. Hence GSV is the major pathway which contains many perforator channels are leading cause of varicose veins.

Analysis of Pathological Classification: In the study we made pathological cause leading to varicosities comes as reflux accounting 49 patients that is $94.2 \%$. Thus primary varicose vein leading cause for pathogenesis of the disease is reflux. The remaining percent is caused by obstruction. So in case of secondary varicose vein the pathogenesis of varicosities being obstruction. Analysis of Doppler Findings: Analysis of this study shows that combination of SFJ and perforator shows the maximum number 29 
patients that is $55.8 \%$ Next in the list comes SFJ alone accounting for 14 patients that is about 26.9 percent This correlates with that of anatomical classification where the involvement of Great Saphenous Vein and perforators are high. Ultrasound abdomen taken was normal and also secondary causes except DVT has been excluded from the study.

Analysis of Surgery: In this study trendelenberg procedure along with stab avulsion is performed in maximum number of patients accounting for 35 patients. Now radio frequency ablation is performed in equal number to open surgeries. In case of secondary varicose vein due to any other cause surgery is contraindicated.

\section{Conclusion}

In my study Varicose veins was relatively common among the youth and middle age groups. Risk factors for the development of varicose veins were prolonged standing and multiparity. Clinical presentations ranged from mild to severe varicosities, with ulcer and lipodermatosclerosis being the most severe forms. At present, Duplex ultrasound scanning is the most reliable investigative tool in making diagnosis of varicose veins in terms of valve incompetence along GSV and SSV, deep vein thrombosis and perforator incompetence. Treatment includes conservative management, sclerotherapy and surgery. Conservative management was advised in patients who are pregnant and patients with contra indications for surgery. These patients were advised to wear compression stockings. Sclerotherapy was advised in patients with reticular veins. Surgical procedure includes Trendlenburg procedure, stripping of the vein and subfacial ligation of the perforators. Surgical intervention has been revolutionized by the development of endovenous techniques like radiofrequency abalation, laserabalation, foamsclerotherapy and subfacial endoscopic perforator surgery.

Declaration of Conflict of Interest: There is no conflict of interest.
Funding: This research received no specific grant from any funding agency in public, commercial, or not-for-profit sectors.

\section{References}

1. De Takatas G. Varicose veins and their sequelae. JAMA 1929; 92(10):775-783. doi:10.1001/jama.1929.02700360013005 Masuda E.M., Kistner R.L., Prospective comparision of Duplex scanning and descending venography in assessment of venous in sufficiency. Am J Surg. 1992 Sep; 164(3):254-9.

2. Shami S.K., Sarin S, Cheatle T.R., Scurr J.H., Coleridge Smith P.D., "Venous ulcers and the superficial system". Journal of Vascular Surgery.1993:17:487-490.

3. Bergam JJ, Yao JST. Edition Surgery of Veins. New York: Grune and Stratton, 1985.

4. Bergan JJ, Yao JST. Venous Disorder. Phiiladelphia: W.B. Saunders, 1991.

5. Bradybury AW, Murie JA, Ruckley CV. Role of leucocyte in the pathogenesis of vascular disease. Br. J Surg, 1993:8: 150312.

6. Browse NZ, Burnand $\mathrm{KG}$, and Lea Thomas M. Diseases of the Veins: Pathology, diagnosis and treatment. London: Arnold, 1988

7. Dodd H, Cockett FB, The pathology and surgery of the veins of the lower limbs. Edinburgh: Churchill Livingstone, 1976.

8. David J. Tibbs Venous disorders, Oxford Textbook of Surgery.

9. Gardener AMN, Fox RH. The return of Blood to Heart : Venous pumps in Health and Disease, London :john Libbey, 1989

10. John H. Scurr, Venous Disorder, Bailey and Love's Short Practice of Surgery.

11. Lea Thomas M. Phelebography of lower limbs. Edinburgh: Churchill Livingstone, 1982.

12. Negus D. Leg Ulcers. Oxford: Butterworth - Heinemann Ltd., 1991.

13. Nicolaides AN, Christopoulors D, 
Vasdekis S. Progress in the investigations of chronic venous insufficiency. Ann Vasc Surg, 1989:3:278-92.

14. Tibbs DJ. Varicose veins and related disorders. Oxford: Butterworth Heinemann Ltd., 1992.

15. Hanahan LM, Araki CT, Rodriguez AA. Et al: Distribution of valvular incompetence in patients with venous stasis ulceration. J Vasc Surg 13:805-512, 1991.

16. Shami SK, Sarin S, Cheatle TR, et al: Venous ulcers and the superficial venous system. J Vasc Surg 17:487 - 490, 1993.

17. Walsh JC, Bergen JJ, Beeman S, et al : Femoral venous reflux abolished by greater saphenous vein stripping. Ann Vasc Surg 8:566-570, 1994. 